Conclusions In this area there was a large unmet need for treatment in patients in care homes with respiratory disease as one of their diagnoses. This project untaken during the covid epidemic has demonstrated that it was possible to provide this in a covid-secure manner and found a need for education of care home staff and a need for a wider application of this project which is now being rolled out to the other CCG (Thurrock) in our area. Educational materials are being produced and distributed to all care homes in the area. The inreach of community respiratory team staff into care homes can be used as an avenue to ensure good education of care home staff and increase vaccination of staff and residents and optimization of therapy for residents to reduce the risk of hospital admission

\section{P161 UNDERSTANDING THE ROLE OF A PATIENT-LED PULMONARY FIBROSIS CHARITY ON ENABLING SUPPORT GROUPS TO THRIVE: A UK WIDE SURVEY OF SUPPORT GROUP LEADERS AND MEMBERS EXPERIENCES}

DA Chand, J Ruck. Action for Pulmonary Fibrosis, Peterborough, UK

\subsection{6/thorax-2021-BTSabstracts. 270}

Introduction Pulmonary fibrosis is a devastating progressive lung scarring disease with poor prognosis. Evidence suggests that peer support, facilitated through disease-specific support groups, has a positive impact on patients and their carers. Charities can play a crucial role in setting up and sustaining such groups. We sought to understand the role of tailored support, provided by a patient-led pulmonary fibrosis charity, on support group leaders (SGLs) and their members.

Methods The charity offers tailored support to 75 independent support groups through grants, guidance and training which aims to empower, increase confidence and ensure quality.

Two surveys were conducted via a 10 minute web-based questionnaire. SGLs completed a 20-item survey and members completed a 12-item survey, requiring 4-point Likert scale and open-ended responses. All SGLs were invited to participate and to share the member survey with their group.

Results 22 SGLs and 81 members participated. 91\% SGLs felt they had the necessary knowledge and skills to support their members but identified training needs in supporting people through loss and change (82\%), and ways to keep positive and motivated (82\%). 55\% did not think they received ongoing referrals to their group and $86 \%$ felt that grants or initiatives to recruit new members or reach isolated patients were important.

Members felt the support group had helped them to feel part of a supportive community (94\%); and more informed about pulmonary fibrosis (94\%) and manage daily symptoms more effectively (90\%).

Conclusions The survey results replicate previous findings that support groups have tangible benefits for patients and carers. Provided with tailored charity support, SGLs feel equipped to support their members, most of whom report a positive impact from being part of a group. Noting the difficulty gaining new members, new initiatives will be needed, working closely with healthcare professionals, to ensure patients can access this important support service.

\section{Topics in thoracic malignancies}

\section{P162 PREPARING WALES FOR LUNG CANCER SCREENING - SELECTING A SEARCH STRATEGY FOR INCLUSION}

${ }^{1}$ JS Engela-Volker, ${ }^{2}$ SR Eccles. ' Cardiff University, Neuadd Meirionnydd, Cardiff, UK; ${ }^{2}$ Royal Glamorgan Hospital, Cwm Taf Morgannwg, Cardiff, UK

\subsection{6/thorax-2021-BTSabstracts.271}

Introduction Lung Health Check (LHC) programmes have used varying invitation strategies, from contacting all patients in the target age range (Manchester), identifying ever-smokers from GP records (NHS England Targeted LHC programme), and inviting people recorded on GP records as a current smoker in the last 20 years (SUMMIT). We modelled the impact different inclusion criteria would have on a future Lung Health Check programme in Wales.

Methods GP records from 6 practices were included. Searches were run varying the age range (50-74 years, 55-74, 60-74) and smoking codes included. Four different search strategies for smoking codes were used: BROAD (including a wide range of current and ex-smoker codes), VOLUME (as for 'BROAD' but excluding the 'trivial ex-smoker' code), FOCUSSED (looking for cigarette-related tobacco codes only), and RECENT (searching for current smoker codes recorded in the last 20 years, to capture current smokers and more recent ex-smokers). We compared the results of these search strategies and extrapolated to the Welsh population.

Results The included practices had a total population of 68,571 , reflecting $2.17 \%$ of the Welsh population. There was negligible difference between the results for the BROAD, VOLUME and FOCUSSED search strategies, with $\leq 0.1 \%$ variation between the strategies. Just over half of patients would be eligible for a LHC using the BROAD strategy, whilst using the RECENT strategy reduced this to around a third. Full results and extrapolation across the Welsh population are shown in table 1.

Conclusions The selection criteria for a future LHC programme in Wales would profoundly influence the number of

Abstract P162 Table 1 Results of search strategies and extrapolation to Welsh population

\begin{tabular}{|c|c|c|c|c|c|c|}
\hline \multirow{2}{*}{$\begin{array}{l}\text { Age } \\
\text { (yrs) } \\
\text { All ages }\end{array}$} & & & \multicolumn{2}{|c|}{$\begin{array}{l}\text { BROAD search } \\
\text { strategy }\end{array}$} & \multicolumn{2}{|c|}{$\begin{array}{l}\text { RECENT search } \\
\text { strategy }\end{array}$} \\
\hline & & & & & & \\
\hline Sample & 68,571 & Sample $=2.2 \%$ of & & & & \\
\hline Wales & $3,152,879$ & Wales population & & & & \\
\hline $50-74$ & & & & & & \\
\hline $\begin{array}{l}\text { Sample } \\
\text { Wales }\end{array}$ & $\begin{array}{l}20,406 \\
938,263\end{array}$ & $\begin{array}{l}29.8 \% \text { of total } \\
\text { population }\end{array}$ & $\begin{array}{l}10,733 \\
493,501\end{array}$ & $\begin{array}{l}52.6 \% \text { of } \\
\text { age } \\
\text { group }\end{array}$ & $\begin{array}{l}6,887 \\
316,663\end{array}$ & $\begin{array}{l}33.7 \% \text { of } \\
\text { age } \\
\text { group }\end{array}$ \\
\hline $55-74$ & & & & & & \\
\hline $\begin{array}{l}\text { Sample } \\
\text { Wales }\end{array}$ & $\begin{array}{l}15,766 \\
724,917\end{array}$ & $\begin{array}{l}23.0 \% \text { of total } \\
\text { population }\end{array}$ & $\begin{array}{l}8,426 \\
387,426\end{array}$ & $\begin{array}{l}53.4 \% \text { of } \\
\text { age } \\
\text { group }\end{array}$ & $\begin{array}{l}5,200 \\
239,095\end{array}$ & $\begin{array}{l}33.0 \% \text { of } \\
\text { age } \\
\text { group }\end{array}$ \\
\hline $60-74$ & & & & & & \\
\hline $\begin{array}{l}\text { Sample } \\
\text { Wales }\end{array}$ & $\begin{array}{l}11,031 \\
507,203\end{array}$ & $\begin{array}{l}16.1 \% \text { of total } \\
\text { population }\end{array}$ & $\begin{array}{l}6,075 \\
279,327\end{array}$ & $\begin{array}{l}55.1 \% \text { of } \\
\text { age } \\
\text { group }\end{array}$ & $\begin{array}{l}3,504 \\
161,113\end{array}$ & $\begin{array}{l}31.8 \% \text { of } \\
\text { age } \\
\text { group }\end{array}$ \\
\hline
\end{tabular}


people eligible. Across Wales the eligible population could vary from 493,000 using an age range of 50-74 years and a broad search strategy, down to 161,000 using an age range of 60-74 years and limiting the search strategy to current and more recent ex-smokers. As radiology reporting capacity may be the limiting factor for a national programme, focussing invitations to those at highest risk may be desirable in the early stages of project development.

\section{P163 PREPARING WALES FOR LUNG CANCER SCREENING - UPDATING GP RECORD SMOKING DATA USING AN AUTOMATED TEXT MESSAGE SYSTEM}

${ }^{1}$ JS Engela-Volker, ${ }^{2}$ SR Eccles. ${ }^{1}$ Cardiff University, Neuadd Meirionnydd, Cardiff, UK; ${ }^{2}$ Royal Glamorgan Hospital, Cwm Taf Morgannwg, Cardiff, UK

\subsection{6/thorax-2021-BTSabstracts.272}

Introduction Targeted lung cancer screening requires identification of current and ex-smokers. In the NHS England Targeted Lung Health Check Programme this relies on smoking history data in GP records. There are concerns about the completeness and accuracy of this data, meaning some eligible people may not be invited. We interrogated GP records at several practices in Wales to examine the completeness of smoking data and used an automated text message system to update smoking data for people with no smoking status recorded.

Methods GP records for patients aged 50 to 74 years $(+364$ days) were searched for the collective tobacco ' 137 ' Read code. Patients with no tobacco-related code were sent a standardised text message with the option of three replies to indicate their smoking status. On successful reply, a tobacco Read code was automatically recorded in the patient record, and a confirmation text including a link to 'Help Me Quit' was sent to the patient.

Results Across six GP practices, 670/20,402 patients (3.3\%) aged 50-74 had no tobacco code recorded. Of these, 293 $(43.7 \%)$ had a validated mobile phone number recorded, of whom 166/293 (56.7\%) successfully replied to the text. Of these, $71 / 166(42.8 \%)$ were current or ex-smokers, including $21(12.7 \%)$ current smokers.

Conclusions An automated text message system was used to successfully update smoking data in patients with no smoking status recorded. Of the respondents, almost half proved to be current or ex-smokers who would be eligible for a Targeted Lung Health Check. This system could be used to improve the completeness of GP records smoking data, particularly as a resource-sparing method at practices with lower levels of data completeness.

\section{P164 OUTCOME OF LUNG NODULE SURVEILLANCE: A BRIEF RETROSPECTIVE REVIEW OF A COHORT OF PATIENTS FOLLOWED-UP ACCORDING TO BTS GUIDELINES}

${ }^{1} \mathrm{~A}$ Perez Augusto, ${ }^{2} \mathrm{~S}$ Datta, ${ }^{2} \mathrm{Y}$ Ling, ${ }^{2} \mathrm{~L}$ McClure, ${ }^{2} \mathrm{D}$ Grieve, ${ }^{2} \mathrm{M}$ Majury. ${ }^{1}$ University of Glasgow, Glasgow, UK; ${ }^{2}$ Royal Alexandra Hospital, Paisley, UK

\subsection{6/thorax-2021-BTSabstracts.273}

Introduction Lung cancer continues to be the leading cause of cancer death in the UK and the 2nd most common cancer diagnosed each year. In 2015, the British Thoracic Society (BTS) published the updated guidelines on lung nodule

\section{STAGE AT DIAGNOSIS: GENERAL POPULATION VS BTS NODULE FOLLOW-UP}

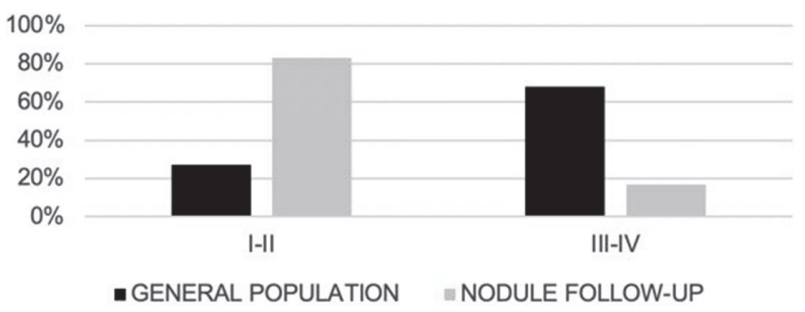

Abstract P164 Figure 1 Comparison between the stages at diagnosis in patients in surveillance programme(grey) vs those in the general population (black)

follow-up with the aim of improving early identification of lung malignancies and improving survival. Here we aim to determine the rate of early cancer detection in patients referred to the lung nodule MDT and explore their outcomes. Methods Patients were identified from the minutes of lung nodule MDTs celebrated during 2018 and information gathered via RIS, PACS and clinical record systems of the hospital.

Results 92 patients were identified using the method described above. The median age of participants was 67.5 (42-88) and there were slightly more females than males (51 to $41 ; 55.4$ to $44.6 \%)$. The rate of compliance with guidelines was very high at $98.9 \%$. We identified 6 lung primary malignancies of which all but 1 (83.3\%) were in early stages (stage I or II), compared to $27 \%$ in lung cancers detected in the population (figure 1). Of the patients with early-stage lung cancer, 3 were judged not fit for active treatment. The other 2 underwent lobectomies and have had more than 2 disease-free years as of the time of this writing.

Conclusion This data shows that implementation of the BTS guidelines in lung nodule follow-up leads to higher rates of early-stage lung cancer detection and improved prognosis for these patients. However, we also note that a relatively high proportion of these detected lung cancers are found in patients with poor functional status making them ineligible for active treatment. We propose that it may be beneficial for future editions of this BTS guidelines to explore including clear entry and retainment criteria for patients which, no matter the outcome, will be unable to withstand active treatment. These could include looking at, for example, elements such as minimum functional or pulmonary status. This would avoid some patients undergoing a 2 to 4 -year-long surveillance programme which will ultimately not affect their management options.

\section{P165 THE 'SUSPICIOUS' CHEST X-RAY. HOW GOOD ARE WE AT DISTINGUISHING HIGH RISK FROM LOW RISK ABNORMALITIES?}

JH Noble, A Rehman, H Steer. Gloucestershire Hospitals NHS Foundation Trust, Gloucester, UK

\subsection{6/thorax-2021-BTSabstracts.274}

Introduction We have developed two parallel direct recall CT pathways for patients with abnormal CXRs - a CX3 (NOLCP) pathway where CXR is suspicious for lung cancer, 